\title{
VARIAÇÕES FLORÍSTICAS E ESTRUTURAIS DE UMA VOÇOROCA EM ITUMIRIM, MINAS GERAIS
}

\author{
Ricardo Ayres Loschi ${ }^{1}$, José Aldo Alves Pereira ${ }^{2}$, Evandro Luiz Mendonça Machado ${ }^{3}$, \\ Leandro Carlos ${ }^{4}$, Rubens Manoel dos Santos ${ }^{5}$
}

(recebido: 11 de dezembro de 2009; aceito: 29 de julho de 2010)

\begin{abstract}
RESUMO: Objetivou-se com este trabalho conhecer e avaliar a composição florística, a estrutura e a diversidade das espécies em regeneração numa voçoroca em Itumirim, MG. A voçoroca possui uma área de 0,9 ha, e foi subdividida em três setores denominados como braços "A"; "B" e "C". Para o levantamento estrutural da vegetação foi empregado o método de agulha, sendo amostrados 574 pontos distribuídos sistematicamente pelos três braços. Cada ponto foi estratificado no terreno em função de um gradiente topográfico. A análise de espécies indicadoras (ISA) foi usada para dar suporte estatístico aos padrões observados. Foi realizado também um levantamento florístico com o propósito de registrar todas as espécies de hábito arbustivo-arbóreo ocorrentes na voçoroca. Por meio do levantamento estrutural verificou-se que as espécies do grupo das "graminóides" e "samambaias" dominaram amplamente todos os setores. A análise de espécies indicadoras realizada para cada um dos braços indicou que Ludwigia elegans (Cambess.) H. Hara apresenta alta fidelidade, e, portanto, pode ser considerada indicadora do setor baixada úmida para o braço " $\mathrm{A}$ " $(\mathrm{p}=0,002)$. O grupo de espécies que compõem a guilda "samambaias" foi considerado indicador do terço superior do braço " $\mathrm{C}$ " $(\mathrm{p}=0,038)$. No levantamento florístico, referente às espécies de hábito arbustivo-arbóreo, foram registradas nos três braços 73 espécies, distribuídas em 63 gêneros e 33 famílias botânicas. As famílias com maiores riquezas de espécies foram Fabaceae, Asteraceae, Melastomataceae e Myrtaceae, representando 46,6\% do total de espécies registradas.
\end{abstract}

Palavras-chave: Áreas degradadas, regeneração natural, método de agulha, fitossociologia, florística.

\section{FLORISTIC AND STRUCTURAL VARIATIONS OF A GULLY AT ITUMIRIM, MINAS GERAIS}

\begin{abstract}
This work aimed at knowing and evaluating the florisitc composition, the strucuture and the diversity of the regenerating species in a gully at Itumirim, $M G$. The gully possesses an area of 0.9 ha and was subdivided into three sectors named as arms "A"; " $B$ " and " $C$ ". For the structural survey of the vegetation the needle method was employed, i. e., 574 points distributed systematically across the three arms were sampled. Each spot was stratified on the terrain as related to a topographic gradient. The indicator species analysis (ISA) was used to give statistical support to the standards found. A florisitic survey was also conducted with the purpose of recording all the species of shrub-tree life form ocorring in the gully. Through the strucutural survey, it was found that the species of the group of "grass-like" and "ferns" dominated widely all the sectors. The indicator species analysis performed for each of the arms pointed out that Ludwigia elegans (Cambess.) H. Hara presents high fidelity, and, therefore, can be regarded as an indicator of the sector slack for arm " $A$ " $(p=0.002)$.the group of species which make up the guild "ferns" was considered an indicator for the upper third of arm " $C$ " $(p=0.038)$. In the floristic survey concerning the species of shrub-tree life form, 73 species were recorded in the three arms arms 73, distributed into 63 genera and 33 botanic families. The families with highest diversities of species were Fabaceae, Asteraceae, Melastomataceae and Myrtaceae, standing for $46.6 \%$ of the total of recorded species.
\end{abstract}

Key words: Degraded areas, natural regeneration, needle method, phytosociology, floristics.

\section{INTRODUÇÃO}

A erosão hídrica é um dos mais ativos processos de degradação ambiental, sobretudo em regiões de clima tropical. A erosão age de formas variadas: da mais sutil, como a laminar, muitas vezes despercebida, até a mais evidente e desastrosa, como a que desenvolve as voçorocas (PARZANESE, 1991). Além da degradação ambiental, essas perdas de solos podem envolver riscos de perdas materiais e de vidas humanas (GIRÃO, 2007; POESEN et al., 2003; SILVA, 2008).

\footnotetext{
${ }^{1}$ Engenheiro Florestal, Mestre em Engenharia Florestal - Departamento de Ciências Florestais/DCF - Universidade Federal de Lavras/ UFLA - Cx. P. 3037 - 37200-000 - Lavras, MG - riloschi@gmail.com

${ }^{2}$ Engenheiro Florestal, Professor Dr. em Impactos Ambientais - Departamento de Ciências Florestais/DCF - Universidade Federal de Lavras/UFLA - Cx. P. 3037 - 37200-000 - Lavras, MG - j.aldo@dcf.ufla.br

${ }^{3}$ Engenheiro Florestal, Professor Dr. em Ecologia - Departamento de Engenharia Florestal/DEF - Universidade Federal dos Vales do Jequitinhonha e Mucuri/UFVJM - Cx. P. 049 - 39100-000 - Diamantina, MG - machadoelm@gmail.com

${ }^{4}$ Engenheiro Florestal, Doutorando em Engenharia Florestal - Departamento de Ciências Florestais/DCF - Universidade Federal de Lavras/UFLA - Cx. P. 3037 - 37200-000 - Lavras, MG - 1cmaestro@gmail.com

${ }^{5}$ Biólogo, Professor Dr. em Ecologia - Departamento de Ciências Florestais/DCF - Universidade Federal de Lavras/UFLA - Cx. P. 3037-37200-000 - Lavras, MG - rubensmanoel@gmail.com
}

Cerne, Lavras, v. 16, n. 4, p. 479-498, out./dez. 2010 
Nos locais afetados pelo voçorocamento, a importância da vegetação, consiste na captação e transformação de energia, que manterá toda a cadeia trófica, gerando sítios ecológicos associados aos fatores ambientais (VANWALLEGHEM et al., 2005). No entanto, a presença da regeneração e o vigor da vegetação dependem da disponibilidade de nutrientes e da umidade do solo, fatores que normalmente se acham em níveis inadequados em áreas erodidas (RESENDE et al., 2007).

Uma das estratégias mais recomendadas em planos de recuperação é a reprodução do padrão natural das comunidades vegetais, aumentando a probabilidade de sucesso na recuperação ambiental, além de contribuir para redução dos custos de projetos (ARAÚJO et al., 2006). Além disso, a estratégia citada contribui para a conservação da biodiversidade regional explorando, protegendo ou mesmo expandindo as fontes naturais de diversidade genética, não só das espécies vegetais em questão, mas também da fauna local a elas associada (OLIVEIRA-FILHO, 1994).

O conhecimento a respeito de espécies vegetais com capacidade de se estabelecer em locais com condições adversas, associadas aos padrões de dispersão e de regeneração natural, é fundamental para o controle dos processos erosivos, ampliando as possibilidades de sucesso nas intervenções direcionadas para a recuperação de áreas degradadas (SEITZ, 1994).

O presente trabalho foi desenvolvido em uma voçoroca localizada no município de Itumirim, MG, a qual foi subdividida em três estágios de colonização. Os objetivos foram conhecer e avaliar a composição florística, a estrutura e a diversidade das espécies em regeneração na voçoroca.

\section{MATERIAL E MÉTODOS}

O presente estudo foi conduzido em uma área sob efeito de erosão hídrica severa, conhecida popularmente como voçoroca, localizada no Município de Itumirim, Minas Gerais. A área encontra-se nas coordenadas de $21^{\circ} 16^{\prime} \mathrm{S}$ e $44^{\circ} 50^{\prime} \mathrm{W}$, com altitude média de $880 \mathrm{~m}$, em uma região de relevo suave. A voçoroca tem uma área de 0,9 ha, que foi subdividida em três setores (Figura 1), os quais serão denominados daqui em diante como braços "A"; "B" e "C". A definição dos mesmos foi realizada tendo como base o nível de atividade erosiva, onde o local "A" é o mais estável, o "B" encontra-se em contínuo avanço e o "C" é intermediário quanto ao padrão de desenvolvimento da atividade erosiva.

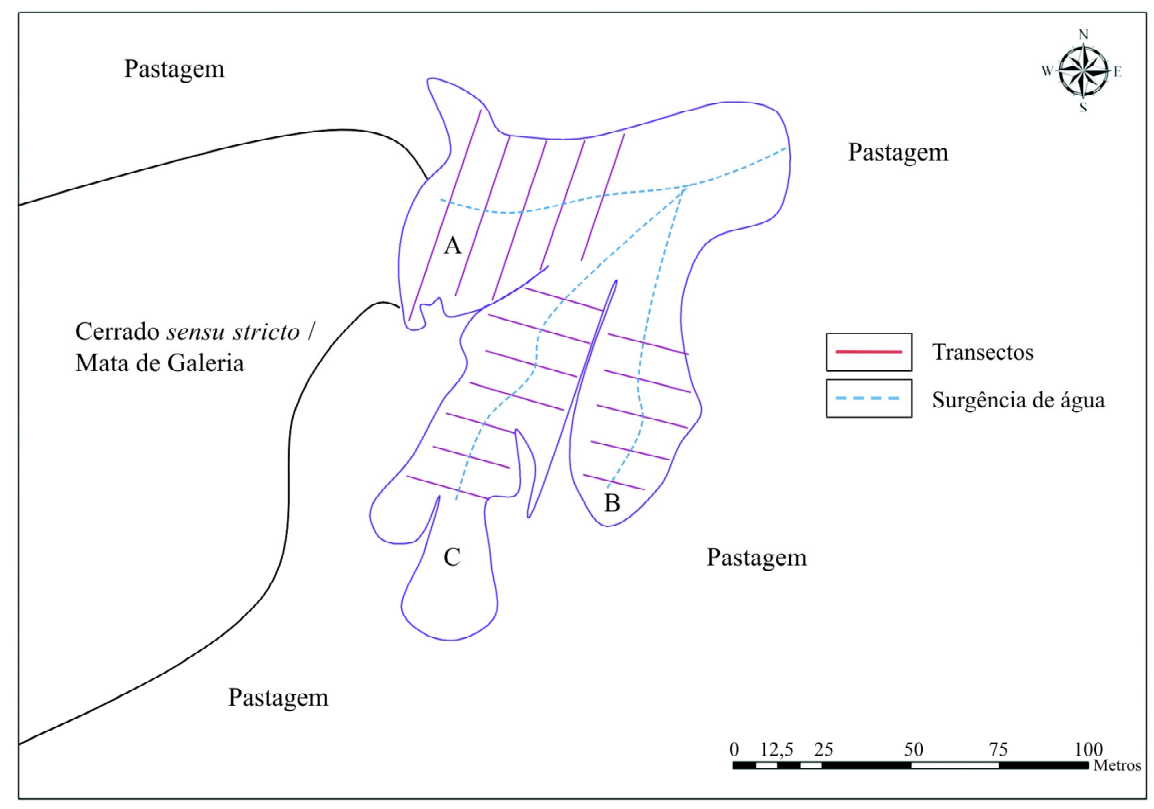

Figura 1 - Mapa mostrando os três braços ("A", "B" e "C") da voçoroca estudada no município de Itumirim, MG, Brasil, enfatizando a localização dos transectos analisados, a surgência de água e o entorno da área de estudo.

Figure 1 - Map showing the three arms ( " $A$ ", " $B$ " and " $C$ ") of the gully studied in the county of Itumirim, MG, Brasil, highlighting the location of the transects analyzed, the emergence of water and the environment of the study area.

Cerne, Lavras, v. 16, n. 4, p. 479-498, out./dez. 2010 
As classes de solo predominantes no local são Latossolos Vermelho-Amarelos e Cambissolos, derivados da alteração do gnaisse-granítico com predominância dos últimos. O clima é de transição entre Cwa e Cwb, de acordo com a classificação climática de Köppen (ANTUNES, 1986), onde Cwa é caracterizado como mesotérmico, com inverno seco e verão chuvoso, no qual a temperatura média do mês mais frio é inferior a $18^{\circ} \mathrm{C}$ e a do mês mais quente é superior a $22^{\circ} \mathrm{C}$, enquanto que no $\mathrm{Cwb}$, a temperatura média do mês mais quente é inferior a $22^{\circ} \mathrm{C}$. A vegetação original da região era composta por um mosaico de diferentes fitofisionomias de cerrados e matas (QUEIROZ et al., 1980; CARVALHO, 1992), as quais foram substituídas por pastagens e culturas agrícolas, restando apenas pequenos fragmentos da vegetação original.

Para avaliação qualitativa e quantitativa dos elementos regenerantes da vegetação foi empregado o método de agulha, baseado no conceito matemático de homogeneidade de uma área, igualmente representada por um ponto, e que vem sendo utilizado em investigações de formações herbáceas, pastagens e na descrição dos estratos inferiores em comunidades mais estratificadas (ALMEIDA \& ARAÚJO, 1997; BUSELATO \& BUENO, 1981; CASTELLANI \& STUBBLEBINE, 1993; FRIZZO \& PORTO, 2004; MANTOVANI, 1987; SÁ, 1996; VIEIRA \& PESSOA, 2001).

Foram amostrados 574 pontos (260 em “A”, $123 \mathrm{em}$ "B" e 191 em "C"). Os pontos foram distribuídos sistematicamente pelos braços em 17 transeções (cinco em "A", cinco em "B" e sete em "C") (Figura 1), dispostos de forma a transpor perpendicularmente o braço em seu sentido de maior declividade, do topo passando pelo vale e terminando no topo novamente (Figura 2). As distâncias foram de $10 \mathrm{~m}$ entre transeções e $1 \mathrm{~m}$ entre pontos. Cada ponto foi estratificado segundo sua localização no terreno (Figura 2), divididos em: baixada úmida - "BU" (onde há surgência de água); terço inferior - "TI" (porção do terreno próximo a surgência de água e a mais baixa da encosta); terço médio - "TM" (porção intermediária da encosta) e terço superior - "TS" (porção mais alta da encosta). Assim, cada transeção possui sete setores, sendo dois terços superiores, dois médios, dois inferiores e uma baixada úmida.

A agulha utilizada possui cerca de $5 \mathrm{~mm}$ de diâmetro e $2 \mathrm{~m}$ de altura e, quando solta verticalmente sobre o solo em cada ponto, são anotadas as espécies tocadas pela mesma e o número de toques. Todos os indivíduos tocados pela agulha, independentemente do seu hábito, foram amostrados. Pontos com solo desnudo também foram considerados, entendendo-se aqui solo desnudo como ponto sem ocorrência de toque. Como o foco do trabalho está relacionado principalmente com as espécies de hábito arbustivo-arbóreo em regeneração na voçoroca, as espécies pertencentes às famílias botânicas Cyperaceae, Eriocaulaceae, Iridaceae e Poaceae foram todas agrupadas como "ervas graminóides" ou apenas "graminóides", assim como as espécies das famílias Dennstaedtiaceae e Gleicheniaceae (pteridófitas) foram agrupadas como "samambaias". Foi realizado também um levantamento florístico em caminhadas de varredura por toda a voçoroca, com o propósito de registrar todas as espécies de hábito arbustivo-arbóreo que não foram observadas no

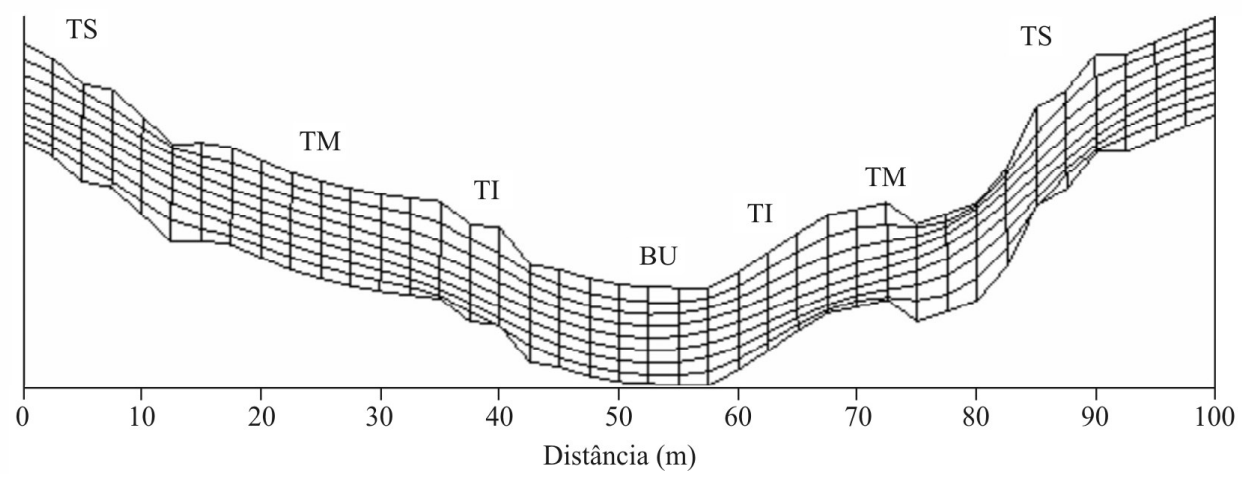

Figura 2 - Diagrama de perfil representando a distribuição dos setores topográficos de uma voçoroca. Onde: BU = baixada úmida; $\mathrm{TI}=$ terço inferior; $\mathrm{TM}=$ terço médio; $\mathrm{TS}=$ terço superior.

Figure 2 - Profile diagram rpresenting the distribution of the topographic sectors of a gully. where: BU = slack; TI=lower third; $T M=$ medium third; $T S=$ upper third . 
levantamento estrutural. As espécies observadas nos braços "A", "B" e "C" foram registradas em função dos seguintes setores: baixada (baixada úmida e terço inferior) e encosta (terço médio e terço superior). Todas as espécies foram coletadas e identificadas por meio de bibliografia especializada, consulta a especialistas e material de herbário, estando as exsicatas dos materiais depositadas no herbário ESAL da Univerisidade Federal de Lavras. As espécies foram classificadas em famílias de acordo com o sistema do Angiosperm Phylogeny Group II (APG, 2003).

As espécies verificadas no levantamento florístico foram classificadas segundo o seu grupo ecológico, adotando-se a metodologia descrita por Swaine \& Whitmore (1988), com modificações sugeridas por OliveiraFilho et al. (1994), nas seguintes categorias: pioneiras (P), clímax exigente de luz (CL) e clímax tolerante à sombra (CS). Quanto às síndromes de dispersão, as espécies foram classificadas, de acordo com Pijl (1982), nas categorias: anemocóricas (Ane), zoocóricas (Zoo) e autocóricas (Aut).

Análise dos dados - Para cada espécie e em cada setor dos três braços da voçoroca, foram obtidos os seguintes parâmetros fitossociológicos: Média de toques: $\mathrm{MTi}=\mathrm{NTi} / \mathrm{NPi}$; Frequência absoluta: FAi $=100 . \mathrm{NPi} /$ NTP; Vigor absoluto: VAi $=100 . \mathrm{NTi} / \mathrm{NTP}$; Índice de cobertura: $\mathrm{ICi}=\mathrm{FAi}+\mathrm{VAi}$. Onde: $\mathrm{NTi}=\mathrm{N}^{\circ}$ de toques da espécie i; $\mathrm{NPi}=\mathrm{N}^{\circ}$ de pontos com a espécie i; NTP $=\mathrm{N}^{\circ}$ total de pontos. A média de toques (MTi) foi obtida a partir da relação entre o número de vezes que a espécie tocou na agulha e o número de pontos onde a espécie ocorreu. Esse parâmetro indica o número médio de estratos da folhagem de uma espécie cobrindo o solo verticalmente (GOODALL, 1952). A frequencia absoluta ou cobertura absoluta (FAi) refere-se à porcentagem de unidades amostrais com ocorrência de uma determinada espécie (como no método de pontos, o toque da agulha indica a cobertura do ponto por um ou mais indivíduos de uma ou mais espécies, esse parâmetro pode expressar tanto a frequência como a cobertura) (MATTEUCCI \& COLMA, 1982). O vigor absoluto (VAi) reflete a estratificação ou a cobertura vertical de uma espécie e depende da sua forma de vida e desenvolvimento. Pode ser usado na indicação da dominância ou notabilidade das espécies, seja por sua altura, cobertura ou densidade (MATTEUCCI \& COLMA, 1982). Por fim, o índice de cobertura (IC) resulta da soma da frequencia absoluta com o vigor absoluto da espécie.

A análise de espécies indicadoras (ISA) (DUFRÊNE \& LEGENDRE, 1997) foi usada para dar suporte estatístico aos padrões observados. A partir do cálculo da abundância relativa e da frequência de ocorrência de cada espécie em cada um dos setores obtém-se um valor indicativo baseado na seguinte fórmula: $\mathrm{Iij}=\mathrm{FOij} \times \mathrm{ARij} \times 100$, onde: $\mathrm{i}=$ espécie analisada; $\mathrm{j}=$ setor analisada; $\mathrm{I}=$ valor indicativo da espécie $i$ no setor $j ; \mathrm{FO}=$ freqüência de ocorrência da espécie $i$ no setor $j$; AR $=$ abundância relativa da espécie $i$ no setor $j$. Os valores obtidos na análise são testados estatisticamente, de forma a diferenciá-los do acaso, pelo teste de Monte Carlo com 1000 repetições (MCCUNE \& MEFFORD, 1997). Com isso, uma espécie só foi considerada indicadora de um setor da voçoroca quando apresentou o maior índice do teste "Indicator Species Analysis" para o referido setor e a significância do teste de Monte Carlo superior a 95\%.

Para efeito de comparação, baseada na composição das espécies de hábito arbustivo-arbóreo registradas na baixada (baixada úmida e terço inferior) e encosta (terço médio e terço superior) dos braços "A", "B" e "C", efetuaram-se cálculos de similaridade utilizando-se o índice de Jaccard (SJ), segundo a fórmula $\mathrm{SJ}=\mathrm{c} /(\mathrm{a}+\mathrm{b}+\mathrm{c})$. Onde: $\mathrm{c}=$ número de espécies em comum entre as amostras; $\mathrm{a}=$ número de espécies exclusivas da amostra $1 ; \mathrm{b}=$ número de espécies exclusivas da amostra 2. De acordo com Brower \& Zar (1984), esse índice é uma medida de simples compreensão, definida pela proporção de espécies em comum.

\section{RESULTADOS E DISCUSSÃO}

No levantamento estrutural, foram registradas, para o estrato arbustivo-arbóreo, nos três braços da área de estudo, 28 espécies, pertencentes a 22 gêneros e 13 famílias botânicas (Tabela 1), com destaque especial para as famílias Asteraceae e Melastomataceae. Farias et al. (1993), estudando voçorocas em Ouro Preto, MG, observaram o mesmo padrão florístico. Gavilanes \& Angieri Filho (1991), em levantamento da flora ruderal em Lavras, MG, município vizinho ao local de estudo, encontraram a família Asteraceae como a de maior número de espécies nesses ambientes alterados, assim como Nappo et al. (2004) avaliando a dinâmica da regeneração natural em área minerada, em Poços de Caldas, MG. Guillaumon \& Fontes (1992) indicam que espécies de melastomatáceas podem ser consideradas como sendo indicadoras de alto grau de deterioração do solo. Nota-se que a maior riqueza de espécies (Tabela 1) encontra-se no braço "A" seguido do "C" e do "B".

Os gêneros Miconia e Baccharis, com quatro e três espécies respectivamente (Tabela 1), foram os mais ricos e comumente se destacam em levantamentos estruturais e

Cerne, Lavras, v. 16, n. 4, p. 479-498, out./dez. 2010 


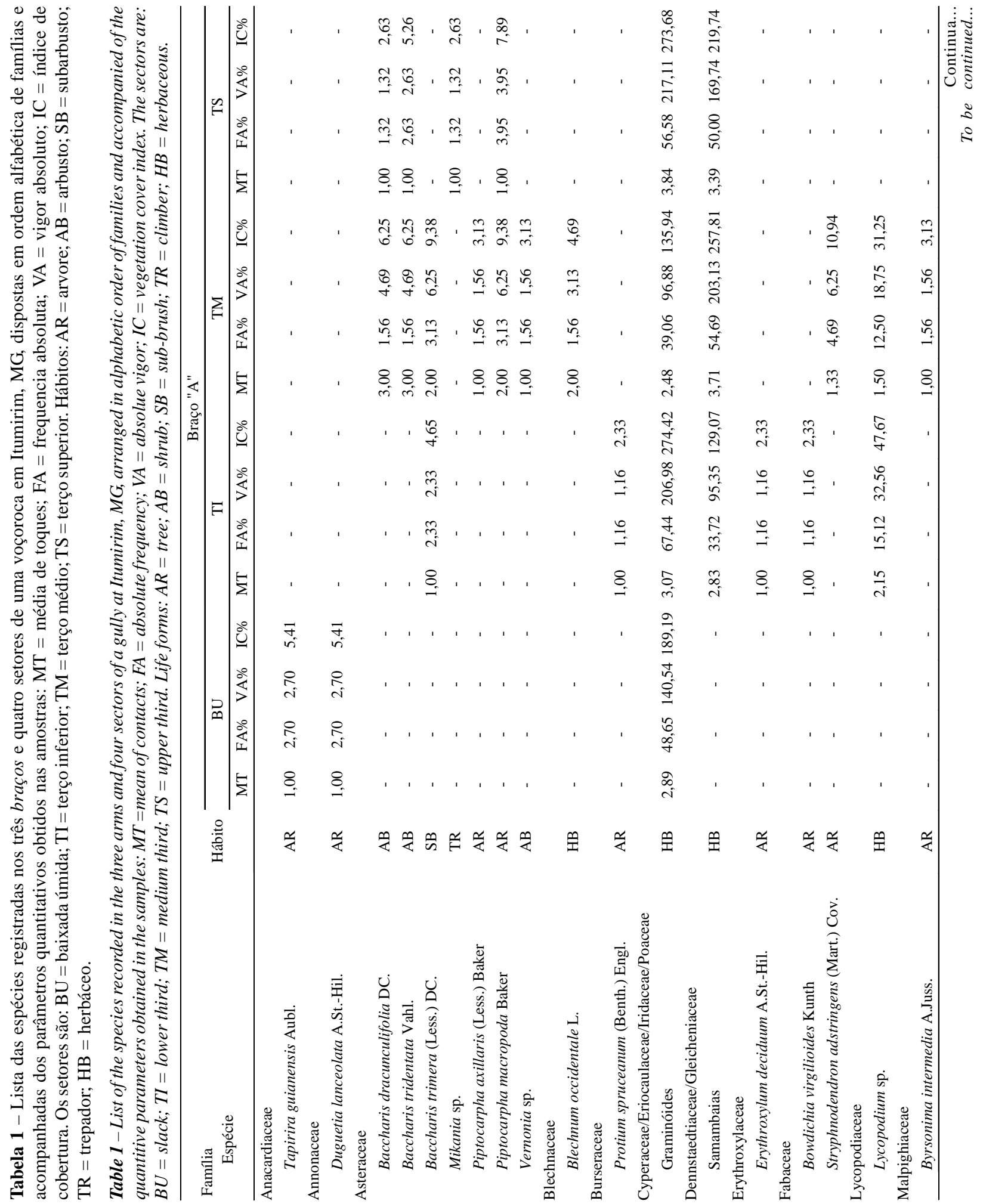




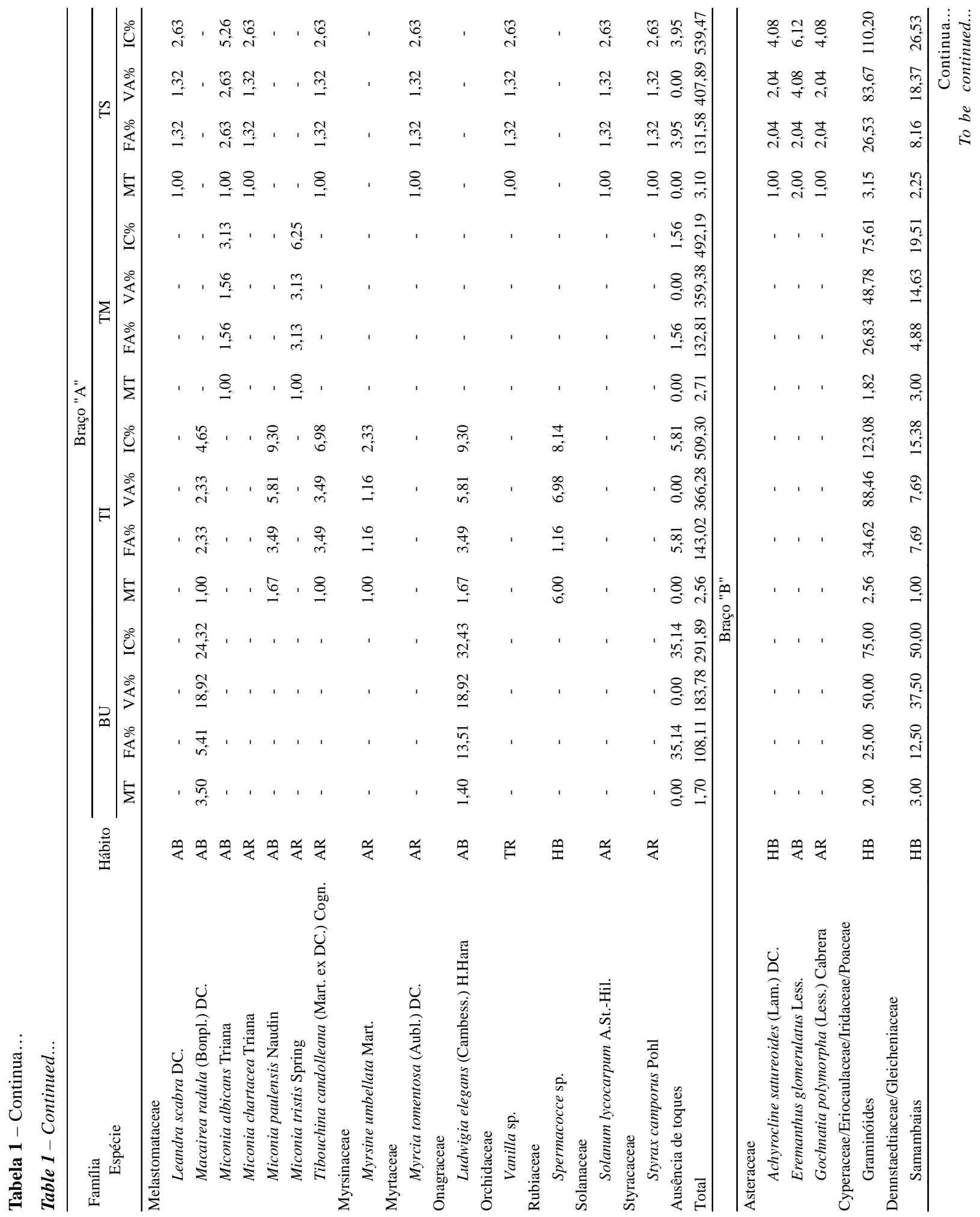

Cerne, Lavras, v. 16, n. 4, p. 479-498, out./dez. 2010 


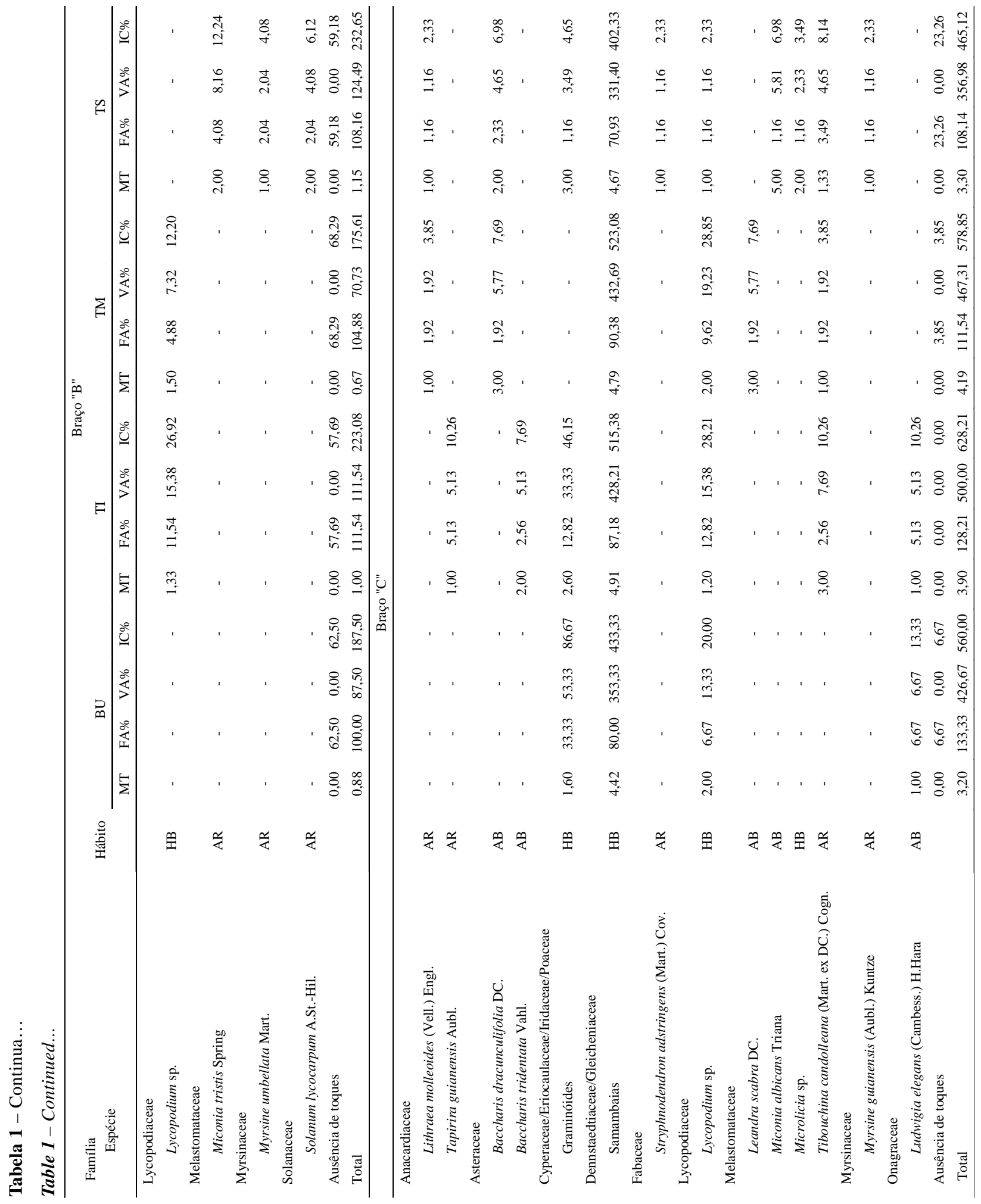

Cerne, Lavras, v. 16, n. 4, p. 479-498, out./dez. 2010 
florísticos realizados em áreas degradadas e/ou perturbadas (FARIAS et al., 1993; NAPPO et al., 2004; RONDON NETO et al., 2000; TABARELLI \& MANTOVANI, 1999). Segundo Rondon Neto et al. (2000), a presença de espécies arbustivas do gênero Baccharis fornece subsídios que contribuem para a afirmação de que a vegetação está em estádio inicial de sucessão, pois estas não ocorrem nos estádios sucessionais mais avançados. Para Klein (1980), estas espécies, após terem atingido um determinado estádio de desenvolvimento, não se estabelecem normalmente, processando-se, nesta fase, a transição para a instalação das primeiras espécies arbóreas. O gênero Miconia é um dos maiores de Melastomataceae no Brasil (SOUZA \& LORENZI, 2005). Podem ser componentes do sub-bosque de florestas primárias, porém ocorrem principalmente em áreas secundárias, bordas de floresta e clareiras naturais no interior de florestas e, por esta razão, podem ser consideradas como espécies pioneiras ou invasoras (ELLISON et al., 1993). Em geral, as plantas desse gênero produzem uma grande quantidade de sementes e suas plântulas podem se estabelecer rapidamente no solo de ambientes degradados (STILES \& ROSSELLI, 1983).

Verifica-se que as diferentes espécies que fazem parte do grupo das "graminóides" e "samambaias" dominaram amplamente todos os setores dos três braços da voçoroca (Tabela 1). No braço "A" as espécies de "graminóides" apresentaram os maiores valores do índice de cobertura em todos os setores, com exceção do terço médio, onde foram suplantadas pelas "samambaias". Em "B", apresentou-se baixa colonização por vegetação, porém, mais uma vez, houve o predomínio das "graminóides". Os maiores valores de índice de cobertura para o braço "B" foram obtidos em todos os setores pelas espécies de "graminóides". Já, o braço "C", foi quase que totalmente colonizado pelas espécies do grupo das "samambaias" (Tabela 1), com os valores de índice de cobertura superiores em todos os setores para esse grupo.

Conforme se observa na Tabela 1, na baixada úmida, em virtude do lençol freático elevado (deficiência de oxigênio), existe uma grande dificuldade no estabelecimento de espécies de hábito arbustivo-arbóreo (FARIAS et al., 1993). Nesse setor, as espécies de "graminóides" só não foram dominantes no braço "C", onde as espécies de "samambaias" apresentaram um maior valor de índice de cobertura. Tal situação, talvez possa ser explicada pelo fato de que a surgência de água na baixada úmida de "C" seja sazonal, diferente do que acontece aos outros dois braços, onde esta surgência ocorre o ano inteiro. Segundo Farias et al. (1993), observando-se a sucessão das espécies sobre a área após o fenômeno da erosão até sua culminância em voçorocas, as gramíneas surgem primeiro e ocupam os fundos das voçorocas, onde há deficiência de drenagem, juntamente com aquelas espécies que participam, em comunidade, das mesmas condições adaptativas ambientais (teores baixos de nutrientes, solo arenoso e lençol freático elevado). Segundo os mesmos autores, nas áreas de baixada, há predominância de gramíneas como, Andropogon bicornis e Aristida sp.. Na baixada úmida (Tabela 1) do braço "B", não foi verificada nenhuma espécie de hábito arbustivo-arbóreo. No entanto, houve a presença da espécie arbustiva Ludwigia elegans nos braços "A" e “C”, bem como as espécies arbóreas Duguetia lanceolata e Tapirira guianensis e a arbustiva Macairea radula ocorrendo em "A". Já, no terço inferior (Tabela 1), mesmo com o domínio das espécies de "graminóides" e "samambaias", já ocorreu um número maior de espécies de hábito arbustivo-arbóreo, com especial destaque para $L$. elegans, exceto em "B", onde novamente não houve a presença de espécie de maior porte.

Analisando os três braços da voçoroca, observa-se que um expressivo número de espécies de hábito arbustivoarbóreo (Bowdichia virgilioides, Byrsonima intermedia, Duguetia lanceolata, Eremanthus glomerulatus, Erythroxylum deciduum, Gochnatia polymorpha, Miconia chartacea, Myrcia tomentosa, Myrsine guianensis, Piptocarpha axillaris, Protium spruceanum, Styrax camporus e Vernonia sp.) ocorreram em um único ponto, sendo estas consideradas raras na amostragem. Mantovani (1987) estudando diferentes fisionomias de cerrado, também registrou um número significativo de espécies ocorrendo em um único ponto. As espécies de hábito arbustivo-arbóreo que ocorreram em mais de um ponto são as seguintes: Ludwigia elegans (11); Tibouchina candolleana (8); Piptocarpha macropoda e Baccharis dracunculifolia (5); Macairea radula, Miconia albicans e Baccharis tridentata (4); Tapirira guianensis, Miconia paulensis, Stryphnodendron adstringens (3); Myrsine umbellata, Leandra scabra, Solanum lycocarpum e Lithraea molleoides (2).

Tibouchina candolleana foi a espécie de hábito arbustivo-arbóreo mais generalista do levantamento estrutural, sendo a única que apareceu em três setores: terços inferior, médio e superior. De acordo com Nappo et al. (2004), T. candolleana e outras espécies avaliadas apresentaram desempenho superior na colonização e estruturação, sendo consideradas importantes nos programas de reabilitação de áreas mineradas.

Cerne, Lavras, v. 16, n. 4, p. 479-498, out./dez. 2010 
As espécies do grupo de "graminóides" e "samambaias" apresentaram as maiores médias de toques, além de ocorrerem na maioria dos pontos. Mantovani (1987) cita a forma de vida, o tamanho do indivíduo e a densidade dos agrupamentos como características que influenciam nos valores obtidos para os números de ocorrência e de toques.

De acordo com Vieira \& Pessoa (2001), a rápida taxa de crescimento, a morfologia e a disposição foliar das gramíneas, além da deposição de grossa camada de folhas mortas, reduzem a disponibilidade de luz ao nível do solo, o que dificulta o estabelecimento e desenvolvimento de sementes e plântulas de elementos lenhosos. Ainda, segundo estes autores, o sistema radicular superficial, peculiar a este grupo, aumenta a competição por nutrientes e água do solo, novamente interferindo no estabelecimento e crescimento de plântulas de indivíduos lenhosos. Purata (1986), estudando a florística e a estrutura de campos abandonados, observou que o favorecimento em direção à ocorrência predominante de espécies ruderais tende a retardar o processo sucessional, dificultando o estabelecimento de árvores de espécies pioneiras. As interações das espécies com o meio e com outras espécies seriam os agentes controladores da invasão e do estabelecimento de espécies arbustivas e arbóreas (MYSTER, 1993), destacando-se, entre estas, a competição entre espécies herbáceas e sementes e plântulas de espécies arbustivas e arbóreas.

Segundo Farias et al. (1993), Gleichenia sp. tornase quase a única espécie nos barrancos íngremes que compõem as paredes das voçorocas, como os observados no braço "C". De acordo com os mesmos autores, essa dominância se dá pelo fato de ela ser uma espécie competente quanto ao recobrimento do solo (seus esporos são pequenos), podendo desenvolver-se em locais com pouca disponibilidade de água e baixa fertilidade. De acordo com Gliessman \& Muller (1978), a espécie Pteridium aquilinum é uma samambaia cosmopolita e extremamente comum no Brasil, cuja capacidade de colonizar ambientes impedindo o estabelecimento de outras espécies vegetais é relacionada ao seu efeito alelopático. Esse mecanismo de dominância estende-se desde os trópicos até as margens de florestas boreais (PERES et al., 2004). P. aquilinum (SAITO \& LUCHINI, 1998), Gleichenia pectinata (PERES et al., 1998) e Gleichenia japonica (MUNESADA et al., 1992) contêm fitotoxinas capazes de interferir na germinação e no crescimento de certas espécies vegetais, possuindo elevada capacidade em colonizar ambientes degradados e com alta atividade antrópica.

Observa-se (Tabela 1) que, ao sair de um ambiente extremamente encharcado para um com maior oxigenação, as espécies de maior porte já ocorrem com mais frequencia (FARIAS et al., 1993). Isso é o que acontece nos terços médio e superior das encostas, com exceção do braço "B", onde nessa voçoroca só existem elementos arbustivoarbóreos no terço superior. De acordo com Parrotta et al. (1997), o estabelecimento da cobertura vegetal arbórea e/ ou arbustiva produz efeito catalítico no processo de reabilitação da área, pois promove mudanças das condições microclimáticas, aumentando a complexidade estrutural da vegetação e o desenvolvimento das camadas de serapilheira e húmus, fazendo com que aumente a chegada de sementes na área e a atratividade dos agentes dispersores e, ao mesmo tempo, estas mudanças geram condições propícias à germinação e desenvolvimento das espécies.

A análise de espécies indicadoras realizada para cada um dos braços indicou que Ludwigia elegans apresenta alta fidelidade (Tabela 2), e, portanto, pode ser considerada indicadora do setor baixada úmida para o braço “A” $(p=0,002)$. A espécie Ludwigia elegans é um arbusto encontrado em locais úmidos e alagados, considerada como uma das principais plantas daninhas em arroz irrigado (EMBRAPA, 2005). Segundo Souza \& Lorenzi (2005), o gênero Ludwigia ocorre por todo o Brasil, principalmente associado a locais alagáveis. O grupo de espécies que compõem a guilda "samambaias" foi considerado indicador do terço superior do braço "C" $(p=0,038)$. Para os demais setores e para o braço "B" não houve mais nenhuma espécie considerada indicadora. $\mathrm{O}$ fato de terem sido encontradas poucas espécies indicadoras para cada setor, é característico de locais em estágio inicial de sucessão, onde a colonização inicial não define de forma clara uma compartimentação do espaço.

No levantamento florístico, referente às espécies de hábito arbustivo-arbóreo encontradas nos três braços, foram identificadas 73 espécies, distribuídas em 63 gêneros e 33 famílias botânicas (Tabela 3). As famílias com maiores riquezas de espécies foram: Fabaceae (10), Asteraceae (9), Melastomataceae (8) e Myrtaceae (7), representando $46,6 \%$ do total de espécies registradas. Os gêneros que apresentaram maior riqueza florística nos três braços foram: Miconia (4), Baccharis (3), Psidium (3), Aegiphila (2), Myrsine (2) e Piptocarpha (2).

Cerne, Lavras, v. 16, n. 4, p. 479-498, out./dez. 2010 


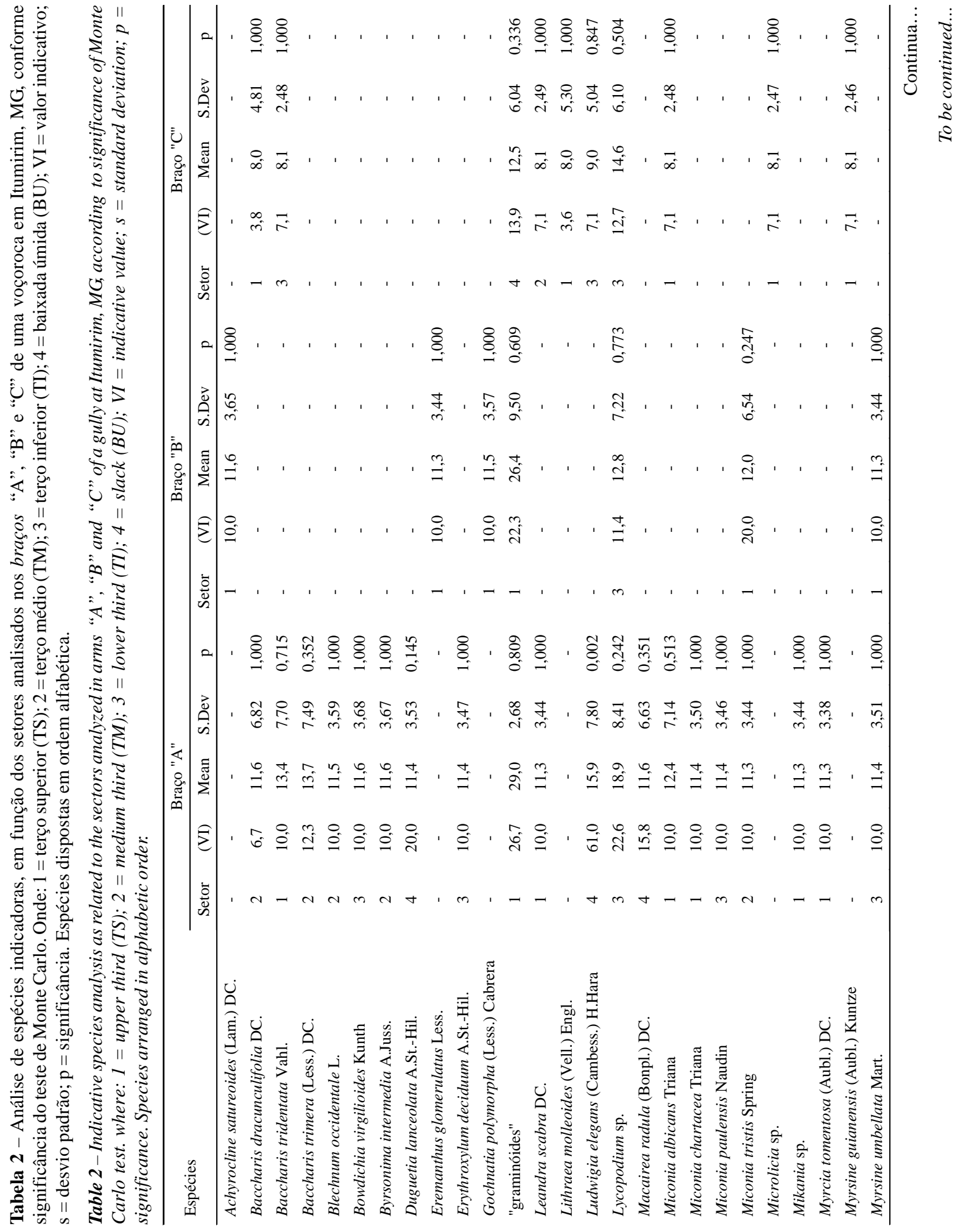

Cerne, Lavras, v. 16, n. 4, p. 479-498, out./dez. 2010 


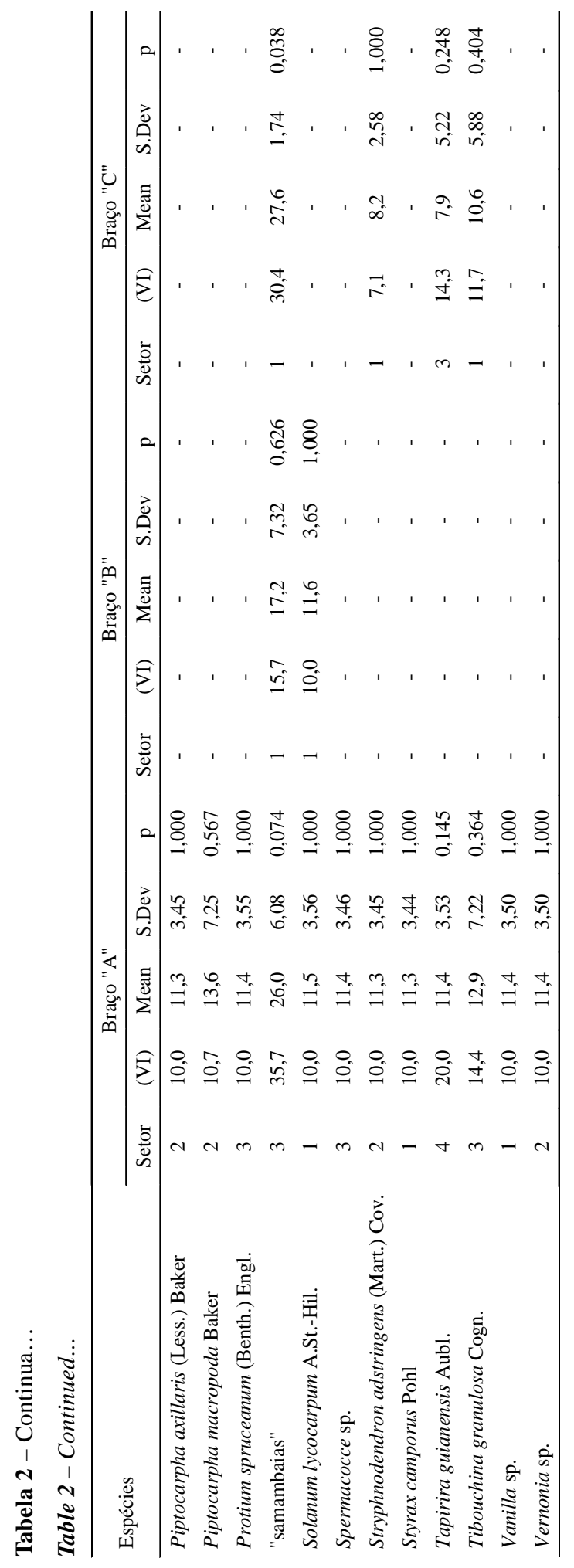

Cerne, Lavras, v. 16, n. 4, p. 479-498, out./dez. 2010 
Tabela 3 - Relação das espécies arbustivo/arbóreas registradas no interior da voçoroca em Itumirim, MG, dispostas em ordem alfabética de família. Em que: $\mathrm{GE}=$ Grupo ecológico $(\mathrm{P}=$ pioneira, $\mathrm{CL}=$ clímax exigente de luz e $\mathrm{CS}=$ clímax tolerante à sombra); $\mathrm{SD}=$ Síndrome de Dispersão (Zoo = zoocórica, Ane = anemocórica e Aut = autocórica). Hábitos: $\mathrm{AR}=$ árvore; $\mathrm{AB}=$ arbusto. Setores: $\mathrm{B}$ = baixada; $\mathrm{E}=$ encosta.

Table 3 - Ratio of the shrub/tree species recorded in the interior of the gully at Itumirim, MG, arranged in alphabetic order of family. In which: $G E=$ Ecologic group $(P=$ pioneer, $C L=$ light-requiring climax and $C S=$ shade-tolerant climax $) ; S D=D i s p e r s a l$ syndrome $(Z o o=$ zoochoric, Ane $=$ anemochoric and Aut = autochoric $)$. Life formss: $A R=$ tree; $A B=$ shrub. Sectors: $B=$ slack; $E=$ sloping land.

\begin{tabular}{|c|c|c|c|c|c|c|c|c|c|}
\hline \multirow{4}{*}{$\begin{array}{l}\text { Família } \\
\text { Espécie }\end{array}$} & \multirow{4}{*}{ Hábito } & \multirow{4}{*}{ GE } & \multirow{4}{*}{ SD } & \multicolumn{6}{|c|}{ Braço } \\
\hline & & & & \multicolumn{2}{|c|}{ "A" } & \multicolumn{2}{|c|}{ "B" } & \multicolumn{2}{|c|}{ "C" } \\
\hline & & & & \multicolumn{2}{|c|}{ Setor } & \multicolumn{2}{|c|}{ Setor } & \multicolumn{2}{|c|}{ Setor } \\
\hline & & & & B & $\mathrm{E}$ & B & $\mathrm{E}$ & B & $\mathrm{E}$ \\
\hline \multicolumn{10}{|l|}{ Acanthaceae } \\
\hline Aphelandra claussenii Wassh. & $\mathrm{AB}$ & $\mathrm{P}$ & Ane & $\mathrm{X}$ & $X$ & & & & \\
\hline \multicolumn{10}{|l|}{ Anacardiaceae } \\
\hline Anacardium humile st. hill. & $\mathrm{AB}$ & CS & Zoo & & & & & & $\mathrm{X}$ \\
\hline Lithraea molleoides (Vell.) Engl. & $\mathrm{AR}$ & CL & Zoo & & $\mathrm{X}$ & & & $\mathrm{X}$ & $\mathrm{X}$ \\
\hline Tapirira guianensis Aubl. & AR & CL & Zoo & $\mathrm{X}$ & $\mathrm{X}$ & & & $\mathrm{X}$ & $\mathrm{X}$ \\
\hline \multicolumn{10}{|l|}{ Annonaceae } \\
\hline Duguetia lanceolata A.St.-Hil. & AR & CS & Zoo & $\mathrm{X}$ & & & & & \\
\hline \multicolumn{10}{|l|}{ Araliaceae } \\
\hline Dendropanax cuneatus (DC.) Decne. \& Planch. & AR & CS & Zoo & & $\mathrm{X}$ & & & & \\
\hline \multicolumn{10}{|l|}{ Asteraceae } \\
\hline Baccharis dentata (Vell.) G.M.Barroso & $\mathrm{AB}$ & $\mathrm{P}$ & Ane & & $\mathrm{X}$ & & & & \\
\hline Baccharis dracunculifolia DC. & $\mathrm{AB}$ & $\mathrm{P}$ & Ane & & $\mathrm{X}$ & & & & $\mathrm{X}$ \\
\hline Baccharis tridentata Vahl. & $\mathrm{AB}$ & $\mathrm{P}$ & Ane & $\mathrm{X}$ & $\mathrm{X}$ & & & $\mathrm{X}$ & \\
\hline Eremanthus glomerulatus Less. & $\mathrm{AB}$ & $\mathrm{P}$ & Ane & & & & $\mathrm{X}$ & $\mathrm{X}$ & $\mathrm{X}$ \\
\hline Gochnatia polymorpha (Less.) Cabrera & AR & $\mathrm{P}$ & Ane & & & & $\mathrm{X}$ & & \\
\hline Piptocarpha axillaris (Less.) Baker & AR & $\mathrm{P}$ & Ane & & $\mathrm{X}$ & & & & \\
\hline Piptocarpha macropoda Baker & AR & $\mathrm{P}$ & Ane & & $\mathrm{X}$ & & & & \\
\hline Vernonanthura phosphorica (Vell.) H.Rob. & $\mathrm{AB}$ & $\mathrm{P}$ & Ane & & & & & & $\mathrm{X}$ \\
\hline Vernonia sp. & $\mathrm{AB}$ & $\mathrm{P}$ & Ane & & $\mathrm{X}$ & & & & \\
\hline \multicolumn{10}{|l|}{ Bignoniaceae } \\
\hline Tabebuia ochracea (Cham.) Standl. & AR & CL & Ane & & $\mathrm{X}$ & & & & \\
\hline \multicolumn{10}{|l|}{ Burseraceae } \\
\hline Protium spruceanum (Benth.) Engl. & AR & $\mathrm{CS}$ & Zoo & $\mathrm{X}$ & $\mathrm{X}$ & & & $\mathrm{X}$ & $\mathrm{X}$ \\
\hline \multicolumn{10}{|l|}{ Clusiaceae } \\
\hline Calophyllum brasiliense Cambess. & AR & $\mathrm{CS}$ & Zoo & $\mathrm{X}$ & & & & & \\
\hline Kielmeyera speciosa A.St.-Hil. & $\mathrm{AR}$ & CL & Ane & & $\mathrm{X}$ & & & $\mathrm{X}$ & $\mathrm{X}$ \\
\hline
\end{tabular}

Cerne, Lavras, v. 16, n. 4, p. 479-498, out./dez. 2010 
Tabela 3 - Continua...

Table 3 - Continued...

\begin{tabular}{|c|c|c|c|c|c|c|c|c|c|}
\hline \multirow{4}{*}{$\begin{array}{l}\text { Família } \\
\text { Espécie }\end{array}$} & \multirow{4}{*}{ Hábito } & \multirow{4}{*}{ GE } & \multirow{4}{*}{$\mathrm{SD}$} & \multicolumn{6}{|c|}{ Braço } \\
\hline & & & & \multicolumn{2}{|c|}{ "A" } & \multicolumn{2}{|c|}{ "B" } & \multicolumn{2}{|c|}{ "C" } \\
\hline & & & & \multicolumn{2}{|c|}{ Setor } & \multicolumn{2}{|c|}{ Setor } & \multicolumn{2}{|c|}{ Setor } \\
\hline & & & & $\mathrm{B}$ & $\mathrm{E}$ & $\mathrm{B}$ & $\mathrm{E}$ & $\mathrm{B}$ & $\mathrm{E}$ \\
\hline \multicolumn{10}{|l|}{ Erythroxylaceae } \\
\hline Erythroxylum deciduum A.St.-Hil. & $\mathrm{AR}$ & $\mathrm{CS}$ & Zoo & $\mathrm{X}$ & & & & & \\
\hline \multicolumn{10}{|l|}{ Fabaceae } \\
\hline Acosmium dasycarpum (Vogel) Yakovlev & $\mathrm{AB}$ & $\mathrm{CL}$ & Ane & & $\mathrm{X}$ & & & & \\
\hline Andira fraxinifolia Benth. & $\mathrm{AR}$ & CL & Zoo & & $X$ & & & $\mathrm{X}$ & \\
\hline Bowdichia virgilioides Kunth & $\mathrm{AR}$ & CL & Ane & $\mathrm{X}$ & & & & $X$ & $\mathrm{X}$ \\
\hline Copaifera langsdorffii Desf. & $\mathrm{AR}$ & $\mathrm{CS}$ & Zoo & $\mathrm{X}$ & $\mathrm{X}$ & & & & $\mathrm{X}$ \\
\hline Dalbergia miscolobium Benth. & $\mathrm{AR}$ & $\mathrm{P}$ & Ane & & $\mathrm{X}$ & & & & \\
\hline Desmodium sp. & $\mathrm{AB}$ & $\mathrm{P}$ & Zoo & $\mathrm{X}$ & & & & & \\
\hline $\begin{array}{l}\text { Leucochloron incuriale (Vell.) Barneby \& } \\
\text { J.W.Grimes }\end{array}$ & $\mathrm{AR}$ & $\mathrm{CL}$ & Aut & & & & & & $\mathrm{X}$ \\
\hline Machaerium villosum Vogel & AR & CL & Ane & & $\mathrm{X}$ & & & & \\
\hline Platypodium elegans Vogel & AR & CL & Ane & & $\mathrm{X}$ & & & & \\
\hline Stryphnodendron adstringens (Mart.) Cov. & $\mathrm{AR}$ & $\mathrm{CS}$ & Zoo & & $\mathrm{X}$ & & & $\mathrm{X}$ & $\mathrm{X}$ \\
\hline \multicolumn{10}{|l|}{ Lacistemataceae } \\
\hline Lacistema hasslerianum Chodat & $\mathrm{AB}$ & $\mathrm{CS}$ & Zoo & $\mathrm{X}$ & $\mathrm{X}$ & & & & \\
\hline \multicolumn{10}{|l|}{ Lamiaceae } \\
\hline Aegiphila sellowiana Cham. & $\mathrm{AR}$ & $\mathrm{P}$ & Ane & & $\mathrm{X}$ & & & & $\mathrm{X}$ \\
\hline Aegiphila verticillata Vell. & $\mathrm{AR}$ & $\mathrm{P}$ & Ane & & $\mathrm{X}$ & & & & \\
\hline \multicolumn{10}{|l|}{ Lauraceae } \\
\hline Aniba firmula (Nees \& Mart.) Mez & $\mathrm{AR}$ & CS & Zoo & $\mathrm{X}$ & & & & & $\mathrm{X}$ \\
\hline \multicolumn{10}{|l|}{ Loganiaceae } \\
\hline Antonia ovata Pohl. & $\mathrm{AB}$ & $\mathrm{P}$ & Ane & $\mathrm{X}$ & & & & & \\
\hline \multicolumn{10}{|l|}{ Lythraceae } \\
\hline Cuphea ingrata Cham. \& Schltdl. & $\mathrm{AB}$ & $\mathrm{P}$ & Zoo & & $\mathrm{X}$ & & & & \\
\hline Diplusodon virgatus Pohl & $\mathrm{AB}$ & $\mathrm{P}$ & Zoo & & $\mathrm{X}$ & & & & \\
\hline \multicolumn{10}{|l|}{ Magnoliaceae } \\
\hline Magnolia ovata (A.St.-Hil.) Sprengel & AR & $\mathrm{CS}$ & Zoo & $\mathrm{X}$ & & & & & \\
\hline \multicolumn{10}{|l|}{ Malpighiaceae } \\
\hline Byrsonima intermedia A.Juss. & AR & $\mathrm{CL}$ & Zoo & & $\mathrm{X}$ & & & $\mathrm{X}$ & \\
\hline \multicolumn{10}{|l|}{ Malvaceae } \\
\hline Bastardiopsis densiflora (Hook. \& Arn.) Hassl. & $\mathrm{AR}$ & $\mathrm{P}$ & Ane & & $\mathrm{X}$ & & & & \\
\hline $\begin{array}{l}\text { Pseudobombax longiflorum (Mart. \& Zucc.) } \\
\text { A.Robyns }\end{array}$ & AR & $\mathrm{CS}$ & Ane & & $\mathrm{X}$ & & & & \\
\hline
\end{tabular}

Continua...

To be continued... 
Tabela 3 - Continua...

Table 3 - Continued...

\begin{tabular}{|c|c|c|c|c|c|c|c|c|c|}
\hline \multirow{4}{*}{$\begin{array}{l}\text { Família } \\
\text { Espécie }\end{array}$} & \multirow{4}{*}{ Hábito } & \multirow{4}{*}{ GE } & \multirow{4}{*}{$\mathrm{SD}$} & \multicolumn{6}{|c|}{ Braço } \\
\hline & & & & \multicolumn{2}{|c|}{ "A" } & \multicolumn{2}{|c|}{ "B" } & \multicolumn{2}{|c|}{ "C" } \\
\hline & & & & \multicolumn{2}{|c|}{ Setor } & \multicolumn{2}{|c|}{ Setor } & \multicolumn{2}{|c|}{ Setor } \\
\hline & & & & $\mathrm{B}$ & $\mathrm{E}$ & $\mathrm{B}$ & $\mathrm{E}$ & $\mathrm{B}$ & $\mathrm{E}$ \\
\hline \multicolumn{10}{|l|}{ Melastomataceae } \\
\hline Leandra scabra DC. & $\mathrm{AB}$ & $\mathrm{CS}$ & Zoo & & $\mathrm{X}$ & & & & $\mathrm{X}$ \\
\hline Macairea radula (Bonpl.) DC. & $\mathrm{AB}$ & $\mathrm{P}$ & Zoo & $\mathrm{X}$ & & & & & \\
\hline Miconia albicans Triana & $\mathrm{AB}$ & $\mathrm{P}$ & Zoo & & $\mathrm{X}$ & & & & $\mathrm{X}$ \\
\hline Miconia chartacea Triana & $\mathrm{AR}$ & $\mathrm{P}$ & Zoo & & $\mathrm{X}$ & & & & \\
\hline Miconia paulensis Naudin & $\mathrm{AB}$ & $\mathrm{P}$ & Zoo & $\mathrm{X}$ & $\mathrm{X}$ & & & & $\mathrm{X}$ \\
\hline Miconia tristis Spring & AR & $\mathrm{P}$ & Zoo & & $X$ & & $X$ & & $\mathrm{X}$ \\
\hline Tibouchina candolleana (Mart. ex DC.) Cogn. & $\mathrm{AR}$ & $\mathrm{P}$ & Ane & $\mathrm{X}$ & & & & $\mathrm{X}$ & $\mathrm{X}$ \\
\hline Trembleya parviflora (D.Don) Cogn. & $\mathrm{AB}$ & $\mathrm{P}$ & Zoo & $\mathrm{X}$ & $\mathrm{X}$ & & & & \\
\hline \multicolumn{10}{|l|}{ Myrsinaceae } \\
\hline Myrsine guianensis (Aubl.) Kuntze & $\mathrm{AR}$ & $\mathrm{CL}$ & Zoo & & & $\mathrm{X}$ & $\mathrm{X}$ & $\mathrm{X}$ & $\mathrm{X}$ \\
\hline Myrsine umbellata Mart. & $\mathrm{AR}$ & CL & Zoo & & $\mathrm{X}$ & & & & \\
\hline \multicolumn{10}{|l|}{ Myrtaceae } \\
\hline Blepharocalyx salicifolius (Kunth) O.Berg & $\mathrm{AR}$ & $\mathrm{P}$ & Zoo & $\mathrm{X}$ & & & & & \\
\hline Calyptranthes brasiliensis Spreng. & $\mathrm{AR}$ & $\mathrm{P}$ & Zoo & & $\mathrm{X}$ & & & & \\
\hline Myrcia tomentosa (Aubl.) DC. & AR & $\mathrm{CL}$ & Zoo & $\mathrm{X}$ & $\mathrm{X}$ & & & & \\
\hline Pimenta pseudocaryophyllus (Gomes) Landrum & $\mathrm{AR}$ & $\mathrm{CL}$ & Zoo & $X$ & & & & & \\
\hline Psidium giganteum Mattos & AR & $\mathrm{P}$ & Zoo & & $\mathrm{X}$ & & & & \\
\hline Psidium guajava $\mathrm{L}$. & $\mathrm{AR}$ & $\mathrm{P}$ & Zoo & & $\mathrm{X}$ & & & & \\
\hline Psidium myrtoides O.Berg & AR & $\mathrm{P}$ & Zoo & & & & & & $\mathrm{X}$ \\
\hline \multicolumn{10}{|l|}{ Nyctaginaceae } \\
\hline Guapira opposita (Vell.) Reitz & AR & $\mathrm{P}$ & Zoo & & & & & $\mathrm{X}$ & \\
\hline \multicolumn{10}{|l|}{ Onagraceae } \\
\hline Ludwigia elegans (Cambess.) H.Hara & $\mathrm{AB}$ & $\mathrm{P}$ & Ane & $\mathrm{X}$ & & & & $\mathrm{X}$ & \\
\hline \multicolumn{10}{|l|}{ Phyllanthaceae } \\
\hline Hieronyma alchorneoides Allemão & $\mathrm{AR}$ & $\mathrm{CL}$ & Aut & $\mathrm{X}$ & & & & & \\
\hline \multicolumn{10}{|l|}{ Peraceae } \\
\hline Pera glabrata (Schott) Poepp. ex Baill. & $\mathrm{AR}$ & $\mathrm{CL}$ & Zoo & & $\mathrm{X}$ & & & & $\mathrm{X}$ \\
\hline \multicolumn{10}{|l|}{ Piperaceae } \\
\hline Piper gaudichaudianum Kunth & $\mathrm{AB}$ & $\mathrm{CL}$ & Zoo & $\mathrm{X}$ & & & & & \\
\hline
\end{tabular}

Cerne, Lavras, v. 16, n. 4, p. 479-498, out./dez. 2010 
Tabela 3 - Continua...

Table 3 - Continued...

\begin{tabular}{|c|c|c|c|c|c|c|c|c|c|}
\hline \multirow{4}{*}{$\begin{array}{l}\text { Família } \\
\text { Espécie }\end{array}$} & \multirow{4}{*}{ Hábito } & \multirow{4}{*}{ GE } & \multirow{4}{*}{ SD } & \multicolumn{6}{|c|}{ Braço } \\
\hline & & & & \multirow{2}{*}{\multicolumn{2}{|c|}{$\begin{array}{c}\text { "A" } \\
\text { Setor }\end{array}$}} & \multirow{2}{*}{\multicolumn{2}{|c|}{$\begin{array}{c}\text { "B" } \\
\text { Setor }\end{array}$}} & \multirow{2}{*}{\multicolumn{2}{|c|}{$\begin{array}{c}\text { "C" } \\
\text { Setor }\end{array}$}} \\
\hline & & & & & & & & & \\
\hline & & & & $\mathrm{B}$ & $\mathrm{E}$ & B & $\mathrm{E}$ & $\mathrm{B}$ & $\mathrm{E}$ \\
\hline \multicolumn{10}{|l|}{ Rubiaceae } \\
\hline Cordiera concolor (Cham.) Kuntze & $\mathrm{AR}$ & $\mathrm{P}$ & Zoo & $\mathrm{X}$ & $\mathrm{X}$ & & & & \\
\hline Ferdinandusa speciosa Pohl & $\mathrm{AR}$ & $\mathrm{CL}$ & Zoo & & $\mathrm{X}$ & & & & $\mathrm{X}$ \\
\hline Rudgea viburnoides (Cham.) Benth. & $\mathrm{AR}$ & $\mathrm{CL}$ & Zoo & & $\mathrm{X}$ & & & & \\
\hline \multicolumn{10}{|l|}{ Sapotaceae } \\
\hline Micropholis venulosa (Mart. \& Eichler) Pierre & AR & $\mathrm{CS}$ & Zoo & & $\mathrm{X}$ & & & & \\
\hline \multicolumn{10}{|l|}{ Siparunaceae } \\
\hline Siparuna guianensis Aubl. & AR & CS & Zoo & & $\mathrm{X}$ & & & $\mathrm{X}$ & $\mathrm{X}$ \\
\hline \multicolumn{10}{|l|}{ Solanaceae } \\
\hline Solanum lycocarpum A.St.-Hil. & $\mathrm{AB}$ & $\mathrm{P}$ & Zoo & & $\mathrm{X}$ & & & & $\mathrm{X}$ \\
\hline \multicolumn{10}{|l|}{ Styracaceae } \\
\hline Styrax camporus Pohl & $\mathrm{AR}$ & $\mathrm{CL}$ & Zoo & $\mathrm{X}$ & $\mathrm{X}$ & & & & \\
\hline \multicolumn{10}{|l|}{ Urticaceae } \\
\hline Cecropia pachystachya Trécul & AR & $\mathrm{P}$ & Zoo & $\mathrm{X}$ & $\mathrm{X}$ & & & $\mathrm{X}$ & $\mathrm{X}$ \\
\hline \multicolumn{10}{|l|}{ Verbenaceae } \\
\hline Duranta vestita Cham. & $\mathrm{AB}$ & $\mathrm{P}$ & Zoo & & $\mathrm{X}$ & & & & \\
\hline Lippia brasiliensis (Link) T. Silva & $\mathrm{AB}$ & $\mathrm{P}$ & Zoo & & & & $\mathrm{X}$ & & $\mathrm{X}$ \\
\hline
\end{tabular}

Miconia tristis foi a única que ocorreu nos três braços, porém apenas na encosta. Já, Tapirira guianensis, Protium spruceanum e Cecropia pachystachya ocorreram, simultaneamente, na baixada e encosta dos braços "A" e "C", bem como Myrsine guianensis ocorreu também, simultaneamente, na baixada e encosta dos braços "B" e "C".

Algumas espécies lenhosas que se destacaram em levantamentos fitossociológicos e florísticos realizados em áreas degradadas e/ou perturbadas (ALVARENGA et al., 2006; ARAÚJO et al., 2006; CORRÊA \& MÉLO FILHO, 2007; FARIAS et al., 1993; GAVILANES \& ANGIERI FILHO, 1991; NAPPO et al., 2004; NERI et al., 2005; PINTO et al., 2005; TABARELLI \& MANTOVANI, 1999; VALCARCEL \& ALTERIO, 1998; VIEIRA \& PESSOA, 2001) também foram registradas nos três braços: Baccharis dracunculifolia, Bowdichia virgilioides, Byrsonima intermedia, Copaifera langsdorffii, Gochnatia polymorpha, Hieronyma alchorneoides, Lithraea molleoides,
Machaerium villosum, Miconia albicans, Platypodium elegans, Piptocarpha macropoda, Psidium guajava, Solanum lycocarpum, Stryphnodendron adstringens, Tapirira guianensis, Tibouchina candolleana, Trembleya parviflora e Vernonia sp..

De maneira geral, os três braços apresentam composição florística de plantas pioneiras (Tabela 3), o que é comum em ambientes degradados e/ou perturbados (FARIAS et al., 1993; ROY, 1990; TABARELLI \& MANTOVANI, 1999).

A predominância das espécies pioneiras verificadas nos três braços indica que elas se encontram em estádio sucessional inicial (CORRÊA \& MÉLO FILHO, 2007). São espécies consideradas como colonizadoras e evidenciam sua importância na fase inicial do processo de recuperação da vegetação.

Considerando as síndromes de dispersão de sementes para as espécies de hábito arbustivo-arbóreo (Tabela 3), observa-se o predomínio da zoocoria (64\%),

Cerne, Lavras, v. 16, n. 4, p. 479-498, out./dez. 2010 
seguido da anemocoria (33\%) e autocoria (3\%), validando a afirmativa de Campello (1998): a maioria das espécies tropicais é dispersa por via zoocórica ou anemocórica. A interação entre a fauna e a vegetação é fundamental no processo de recuperação de áreas degradadas (GUEDES et al., 1997) e deve ser considerada durante o planejamento de projetos de reabilitação das áreas, já que exerce função essencial na dispersão de sementes de remanescentes próximos, contribuindo para a regeneração florestal (MEDELLÍN \& GAONA, 1999; PARROTTA et al., 1997; WUNDERLE JUNIOR, 1997). Segundo Chada et al. (2004), critérios como a capacidade de estabelecimento em condições limitantes, o crescimento rápido, a grande deposição de serapilheira e a atração de fauna são características desejáveis de espécies para plantios de reabilitação.

Por meio do índice de similaridade de Jaccard (SJ) para as espécies registradas no levantamento florístico, verificou-se que há uma maior similaridade florística entre a baixada e encosta do braço "C" seguida das encostas de "A" e "C", onde os valores foram, respectivamente, 34,4\% e $28,8 \%$ (Tabela 4). Considerando-se que $25 \%$ é o limite mínimo para duas áreas serem consideradas floristicamente semelhantes (MÜLLER-DOMBOIS \& ELLENBERG, 1974), pode-se afirmar que os valores de similaridade encontrados para as duas situações acima não são baixos. Os resultados observados entre os setores baixada e encosta de "C" indicam uma maior semelhança das condições ambientais nessa área. Tal afirmação pode ser reforçada pela surgência de água na baixada dessa área ser sazonal, diferentemente do que acontece nos braços "A" e "B", onde a surgência ocorre durante todo o ano. Com relação à similaridade florística entre as encostas dos braços "A" e "C" é bem possível que seja o regime de água o principal fator ambiental associado à presença das espécies de hábito arbustivo-arbóreo (FARIAS et al., 1993). Todas as demais comparações apresentaram valores de similaridades considerados baixos (Tabela 4).

O modelo clássico de sucessão envolve uma substituição de grupos de espécies ao longo do tempo, à medida que as espécies predecessoras fornecem condições mais favoráveis para a invasão e estabelecimento de espécies mais tardias. Este é conhecido como o modelo de "substituição de espécies" de Egler (1954), e se dá por estágios mais definidos e discretos. Assim, as espécies invadem lentamente a área disponível à colonização e facilitam o estabelecimento de outras espécies, pois agem como abrigo para vetores de dispersão, melhoram as condições de fertilidade do solo e fornecem habitats adequados ao recrutamento. Em contrapartida, Woods (1989) considera que a regeneração de espécies florestais depende da capacidade das mesmas em vencerem a competição com as espécies herbáceas e gramíneas. Essas afirmações corroboram a hipótese de Finegan (1984), para o qual um conjunto de processos está envolvido nas transformações florísticas observadas durante o processo de regeneração, as quais ocorrem muito lentamente, como o presente estudo possibilita observar.

Tabela 4 - Número de espécies em comum (lado superior direito) e índices de similaridade florística de Jaccard (lado inferior esquerdo) entre os setores baixada e encosta dos braços "A", "B" e "C" de uma voçoroca em Itumirim, MG. Onde: BA = baixada do braço "A"; $\mathrm{EA}=$ encosta do braço "A"; $\mathrm{BB}$ = baixada do braço "B"; $\mathrm{EB}=$ encosta do braço "B"; $\mathrm{BC}=$ baixada do braço "C"; $\mathrm{EC}=$ encosta do braço "C".

Table 4 - Number of species in common (right upper side) and Jackard's florisitic similarity index (ledt lower side) among the sectors slack and sloping land of arms " $A$ ", " $B$ " and " $C$ " of a gully at Itumirim, $M G$. Where: $B A=$ sloping land of arm " $A$ "; $E A=$ sloping land of arm " $A$ "; $B B=$ sloping land of arm " $B$ "; $E B=$ sloping land of arm " $B$ "; $B C=$ sloping land of arm " $C$ "; $E C=$ sloping land of arm " $C$ ".

\begin{tabular}{|c|c|c|c|c|c|c|}
\hline Setores & BA & EA & BB & EB & $\mathrm{BC}$ & EC \\
\hline $\mathrm{BA}$ & - & 12 & 1 & & 7 & 8 \\
\hline EA & $18,8 \%$ & - & 0 & 1 & 10 & 17 \\
\hline $\mathrm{BB}$ & $4,5 \%$ & $0,0 \%$ & - & 1 & 1 & 1 \\
\hline EB & $0,0 \%$ & $2,3 \%$ & $20,0 \%$ & - & 2 & 4 \\
\hline $\mathrm{BC}$ & $19,4 \%$ & $18,2 \%$ & $6,3 \%$ & $10,5 \%$ & - & 11 \\
\hline $\mathrm{EC}$ & $17,4 \%$ & $28,8 \%$ & $3,7 \%$ & $14,3 \%$ & $34,4 \%$ & - \\
\hline
\end{tabular}

Cerne, Lavras, v. 16, n. 4, p. 479-498, out./dez. 2010 


\section{CONCLUSÕES}

As diferentes espécies que fazem parte do grupo das "graminóides" e "samambaias" dominaram amplamente todos os setores dos três braços da voçoroca.

Tibouchina candolleana foi a espécie de hábito arbustivo-arbóreo mais generalista do levantamento estrutural, já que foi a única que apareceu em três setores: terços inferior, médio e superior.

A espécie Ludwigia elegans na baixada úmida do braço "A" e as espécies de "samambaias" no terço superior do braço "C" foram consideradas como espécies indicadoras destes ambientes.

De maneira geral, os três braços apresentam composição florística de plantas pioneiras. Considerando as síndromes de dispersão de sementes para as espécies de hábito arbustivo-arbóreo, observa-se o predomínio da zoocoria, seguido da anemocoria e autocoria. Foi registrada maior similaridade florística entre a baixada e encosta do braço "C" seguida das encostas de "A" e "C".

As condições ambientias mais restritivas da baixada úmida, dificulta o estabelecimento de espécies de hábito arbustivo-arbóreo, e favorecem o estabelceimento e predominio de ervas "graminóides" e "samambaias".

As espécies arbustivo-arbóreas encontradas no levantamento estrutural e florístico podem ser de grande utilidade na recuperação de voçorocas, já que apresentam indícios de capacidade de se desenvolverem em condições ambientais não muito favoráveis ou extremas para a sobrevivência de outros vegetais.

\section{AGRADECIMENTOS}

Os autores agradecem à Fundação de Amparo à Pesquisa do Estado de Minas Gerais (FAPEMIG), pelo financiamento ao Projeto (CRA - APQ-3604-5.03/07), à Coordenação de Aperfeiçoamento de Pessoal de Nível Superior (CAPES) pela concessão de bolsa de estudos ao primeiro autor e ao Sr. Sílvio Donizete Rezende, por autorizar a realização deste estudo em sua propriedade.

\section{REFERÊNCIAS BIBLIOGRÁFICAS}

ALMEIDA, A. L.; ARAÚJO, D. S. D. Comunidades vegetais do cordão arenoso externo da Reserva Ecológica Estadual de Jacarepiá, Saquarema, RJ. Oecologia Brasiliensis, Rio de Janeiro, v. 3, n. 1, p. 47-63, 1997.

AlVARENGA, A. P.; BOTElHO, S. A.; PEREIRA, I. M. Avaliação da regeneração natural na recomposição de matas ciliares em nascentes na região sul de Minas Gerais. Cerne, Lavras, v. 12, n. 4, p. 360-372, out./dez. 2006.
ANGIOSPERM PHYLOGENY GROUP. An update of the Angiosperm Phylogeny Group classification for the orders and families of flowering plants: APG II. Botanical Journal of the Linnean Society, London, v. 141, n. 4, p. 399-436, Apr. 2003.

ANTUNES, F. Z. Caracterização climática do Estado de Minas Gerais. Informe Agropecuário, Belo Horizonte, v. 12, n. 138, p. 9-13, jun. 1986.

ARAÚJO, F. S.; MARTINS, S. V.; MEIRA NETO, J. A. A.; LANI, J. L.; PIRES, I. E. Estrutura da vegetação arbustivo-arbórea colonizadora de uma área degradada por mineração de caulim, Brás Pires, MG. Revista Árvore, Viçosa, v. 30, n. 1, p. 107-116, jan./fev. 2006.

BROWER, J. E.; ZAR, J. H. Field and laboratory methods for general ecology. 2. ed. Dubuque: W.C. Brown, 1984. 225 p.

BUSELATO, T. C.; BUENO, O. L. Composição florística de dois campos localizados no município de Montenegro, Rio Grande do Sul, Brasil. Iheringia Série Botânica, Porto Alegre, v. 26, p. 65-84, 1981.

CAMPELLO, E. F. C. Sucessão vegetal na recuperação de áreas degradadas. In: DIAS, L. E.; MELLO, J. W. V. (Eds.). Recuperação de áreas degradadas. Viçosa, MG: UFV, 1998. p. 183-196.

CARVALHO, D. A. Flora fanerogâmica de campos rupestres da Serra da Bocaina, Minas Gerais: caracterização e lista de espécies. Ciência e Prática, Lavras, v. 16, n. 1, p. 97-122, jan./jun. 1992.

CASTEllani, T. T.; STUBblebine, W. H. Sucessão secundária inicial em mata mesófila, após perturbação por fogo. Revista Brasileira de Botânica, São Paulo, v. 16, n. 2, p. 181203, fev. 1993.

CHADA, S. S.; CAMPELLO, E. F. C.; FARIA, S. M. Sucessão vegetal em uma encosta reflorestada com leguminosas arbóreas em Angra dos Reis, RJ. Revista Árvore, Viçosa, v. 28, n. 6, p. 801-809, nov./dez. 2004.

CORRÊA, R. S.; MÉLO FILHO, B. Levantamento florístico do estrato lenhoso das áreas mineradas no Distrito Federal. Revista Árvore, Viçosa, v. 31, n. 6, p. 1099-1108, nov./dez. 2007.

DUFRÊNE, M.; LEGENDRE, P. Species assemblages and indicator species: the need for a flexible asymmetrical approach. Ecological Monographs, Lawrence, v. 67, n. 3, p. 345-366, June 1997.

Cerne, Lavras, v. 16, n. 4, p. 479-498, out./dez. 2010 
EGLER, F. E. Vegetation science concepts: I., initial floristic composition, a factor in old-field vegetation development. Vegetatio, The Hague, v. 12, n. 7, p. 412-417, 1954.

ELLISON, A. M.; DENSLOW, J. S.; LOISELLE, B. A.; BRÉNES, D. M. Seed and seedling ecology of Neotropical Melastomataceae. Ecology, Washington, v. 74, n. 6, p. 733-1749, Dec. 1993.

EMPRESA BRASILEIRA DE PESQUISA AGROPECUÁRIA. Cultivo do arroz irrigado no Brasil: plantas daninhas em arroz irrigado. Rio de Janeiro, 2005. Disponível em: <http:// sisistemasdeproducao.cnptia.embrapa.br/Fontes HTML/Arroz/ ÁrrozIrrigadoBrasil/cap11 103 入 Acesso em: 3 dez. 2008.

FARIAS, C. A.; RESENDE, M.; BARROS, N. F.; SILVA, A. F. Dinâmica da revegetação natural de voçorocas na região de Cachoeira do Campo, município de Ouro Preto-MG. Revista Árvore, Viçosa, v. 17, n. 3, p. 314-326, maio/jun. 1993.

FINEGAN, B. Succession. Nature, London, v. 312, p. 109-115, nov. 1984.

FRIZZO, T. C. E.; PORTO, M. L. Zoneamento da vegetação e sua relação com a ocorrência de estruturas mineralizadas na mina Volta Grande, Lavras do Sul, RS, Brasil. Iheringia Série Botânica, Porto Alegre, v. 59, n. 1, p. 5-12, mar. 2004.

GAVILANES, M. L.; ANGIERI FILHO, C. N. d'. Flórula ruderal da cidade de Lavras, MG. Acta Botanica Brasilica, São Paulo, v. 5, n. 2, p. 77-88, fev. 1991.

GIRÃO, O. Análise de processos erosivos em encostas na zona sudoeste da cidade do Recife, Pernambuco. 2007. 305 p. Tese (Doutorado em Geografia) - Universidade Federal do Rio de Janeiro, Rio de Janeiro, 2007.

GLIESSMAN, S. R.; MULLER, C. H. The allelopathic mechanisms of dominance in bracken (Pteridium aquilinum) in southern California. Journal of Chemical Ecological, New York, v. 4, n. 3, p. 337-362, 1978.

GOODALL, D. W. Some considerations in the use of point quadrats for the analysis of vegetation. Australian Journal of Scientific Research, Melbourne, v. 5, n. 1, p. 1-41, 1952.

GUEDES, M. C.; CAMPELLO, E. F.; MELO, V. A.; GRIFFITH, J. J. Seleção de espécies para recuperação de áreas degradadas por meio de ilhas de vegetação. In: SIMPÓSIO NACIONAL DE

Cerne, Lavras, v. 16, n. 4, p. 479-498, out./dez. 2010
RECUPERAÇÃO DE ÁREAS DEGRADADAS, 3., 1997, Viçosa, MG. Anais... Viçosa, MG: SOBRADE/UFV, 1997. p. 279-282.

GUILLAUMON, J. R.; FONTES, M. A. Estudo para manejo dos campos antrópicos do Parque Estadual da Ilha Anchieta, zona de recuperação. In: CONGRESSO NACIONAL SOBRE ESSÊNCIAS NATIVAS, 2., 1992, São Paulo. Anais... São Paulo: Instituto Florestal, 1992. p. 867-879.

KLEIN, R. M. Ecologia da flora e vegetação do Vale do Itajaí. Sellowia, Itajaí, v. 32, p. 165-389, 1980.

MANTOVANI, W. Análise florística e fitossociológica do estrato herbáceo-subarbustivo do cerrado na Reserva Biológica de Mogi-Guaçu e Itirapina, SP. Campinas: Unicamp, 1987. 203 p.

MATTEUCCI, S. D.; COLMA, A. Metodologia para el estudio de la vegetacion. Washington: Secretaria General de la Organización de los Estados Americanos, 1982. 169 p.

MCCUNE, B.; MEFFORD, M. J. Multivariate analysis of ecological data. Version 3.0. Glenden Beach: MJM, 1997. Software.

MEDELLÍN, R. A.; GAONA, O. Seed dispersal by bats and birds in forest and disturbed habitats of Chiapas, México. Biotropica, Washington, v. 31, n. 3, p. 478-485, Mar. 1999.

MÜLLER-DOMBOIS, D.; ELLENBERG, H. Ains and methods of vegetation ecology. New York: J. Wiley, 1974. 574 p.

MUNESADA, K.; SIDDIQUI, H. L.; SUGA, T. Biologically active labdane-type diterpene glycosides from the rootstalks of Gleichenia japonica. Phytochemistry, Oxford, v. 31, n. 5, p. 1533-1536, May 1992.

MYSTER, R. W. Tree invasion and establishment in old field at Hutcheson Memorial Forest. The Botanical Review, Bronx, v. 59, n. 4, p. 251-272, Oct./Dec. 1993.

NAPPO, M. E.; GRIFFITH, J. J.; MARTINS, S. V.; MARCO JÚNIOR, P.; SOUZA, A. L.; OLIVEIRA FILHO, A. T. Dinâmica da estrutura fitossociológica da regeneração natural em sub-bosque de Mimosa scabrella Bentham em área minerada, em Poços de Caldas, MG. Revista Árvore, Viçosa, v. 28, n. 6, p. 811-829, nov./dez. 2004. 
NERI, A. V.; CAMPOS, E. P.; DUARTE, T. G.; MEIRA NETO, J. A. A.; SILVA, A. F.; VALENTE, G. E. Regeneração de espécies nativas lenhosas sob plantio de Eucalyptus em área de Cerrado na Floresta Nacional de Paraopeba, MG, Brasil. Acta Botanica Brasilica, São Paulo, v. 19, n. 2, p. 369-376, fev. 2005.

OLIVEIRA-FILHO, A. T. Estudos ecológicos da vegetação como subsídios para programas de revegetação com espécies nativas: uma proposta metodológica. Cerne, Lavras, v. 1, n. 1, p. 64-72, 1994.

OLIVEIRA-FILHO, A. T.; VILELA, E. A.; CARVALHO, D. A.; GAVILANES, M. L. Effects of soils and topography on the distribution of tree species in a tropical riverine forest in southeastern Brazil. Journal of Tropical Ecology, Cambridge, v. 10, n. 4, p. 483-508, Aug. 1994.

PARROTTA, J. A.; TURNBULL, J. W.; JONES, N. Catalyzing native forest regeneration on degraded tropical lands. Forest Ecology and Management, Amsterdam, v. 99, n. 1/2, p. 1-7, 1997.

PARZANESE, G. A. C. Gênese e desenvolvimento de voçorocas em solos originados de rochas granitóides na região de Cachoeira do Campo, Minas Gerais. 1991. 117 p. Dissertação (Mestrado em Solos e Nutrição de Plantas) Universidade Federal de Viçosa, Viçosa, 1991.

PERES, M. T. L. P.; PIZZOLATTI, M. G.; QUEIROZ, M. H.; YUNES, R. A. Potencial de atividade alelopática de Gleichenia pectinata Willd (Pr.). Pesquisa Agropecuária Brasileira, Brasília, v. 33, n. 2, p. 131-137, fev. 1998.

PERES, M. T. L. P.; SILVA, L. B.; FACCENDA, O.; HESS, S. Potencial alelopático de espécies de Pteridaceae (Pteridophyta). Acta Botanica Brasilica, São Paulo, v. 18, n. 4, p. 723-730, abr. 2004.

PIJL, L. van der. Principles of dispersal in higher plants. 3. ed. Berlin: Springer-Verlag, 1982. 199 p.

PINTO, L. V. A.; BOTELHO, S. A.; OLIVEIRA FILHO, A. T.; DAVIDE, A. C. Estudo da vegetação como subsídio para propostas de recuperação das nascentes da bacia hidrográfica do ribeirão Santa Cruz, Lavras, MG. Revista Árvore, Viçosa, v. 29, n. 6, p. 775-794, nov./dez. 2005.

POESEN, J.; NACHTERGAELE, J.; VERSTRAETEN, G.; VALENTIN, C. Gully erosion and environmental change: importance and research needs. Catena, Leuven, v. 50, p. 91133, 2003.
PURATA, S. E. Floristic and structural changes during old-field succession in the Mexican tropics in relation to site history and species availability. Journal of Tropical Ecology, Cambridge, v. 2, p. 257-276, 1986.

QUEIROZ, R.; SOUZA, A. G.; SANTANA, P.; ANTUNES, F. Z.; FONTES, M. Zoneamento agroclimático do Estado de Minas Gerais. Belo Horizonte: Epamig, 1980. 114 p.

RESENDE, M. N.; CURI, N.; REZENDE, S. B.; CORRÊA, G. F. Pedologia: base para distinção de ambientes. Lavras: UFLA, 2007. 322 p.

RONDON NETO, R. M.; BOTELHO, S. A.; FONTES, M. A. L.; DAVIDE, A. C.; FARIA, J. M. R. Estrutura e composição florística da comunidade arbustivo-arbórea de uma clareira de origem antrópica, em uma floresta estacional semidecídua montana, Lavras-MG, Brasil. Cerne, Lavras, v. 6, n. 2, p. 79-94, jul./dez. 2000.

ROY, J. In search of the characteristics of plant invaders. In: CASTRI, F. D. I.; HANSEN, A. J.; DEBUSSCHE, M. (Eds.). Biological invasion in Europe and Mediterranean Basin. Dordrecht: Kluwer Academic, 1990. p. 335-352.

SÁ, C. F. C. Regeneração em área de floresta de restinga na Reserva Ecológica Estadual de Jacarepiá, Saquarema, RJ: I., estrato herbáceo. Arquivos Jardim Botânico do Rio Janeiro, Rio de Janeiro, v. 34, n. 1, p. 177-192, jun. 1996.

SAITO, M. L.; LUCHINI, F. Substâncias obtidas de plantas e a procura por praguicidas eficientes e seguros ao meio ambiente. Jaguariúna: Embrapa-CNPMA, 1998. 46 p.

SEITZ, R. A. A regeneração natural na recuperação de áreas degradadas. In: SIMPÓSIO SUL AMERICANO, 1.; SIMPÓSIO NACIONAL DE RECUPERAÇÃO DE ÁREAS DEGRADADAS, 2., 1994, Foz do Iguaçu. Anais... Curitiba: FUPEF, 1994. p. 103-110.

SILVA, A. M. Potencial natural de erosão no município de Sorocaba, SP, Brasil. Revista Internacional de Desastres Naturales, Accidentes e Infraestructura Civil, Porto Rico, v. 8, p. 93-101, 2008.

SOUZA, V. C.; LORENZI, H. Botânica sistemática: guia ilustrado para identificação das famílias de Angiospermas da flora brasileira, baseado em APG II. Nova Odessa: Instituto Plantarum, 2005. 640 p.

Cerne, Lavras, v. 16, n. 4, p. 479-498, out./dez. 2010 
STILES, F. G.; ROSSELLI, L. Consumption of fruits of the Melastomataceae by birds: how diffuse is coevolution? Vegetatio, Dordrecht, v. 107/108, n. 1, p. 57-75, June 1983.

SWAINE, M. D.; WHITMORE, T. C. On the definition of ecological species groups in Tropical Rain Forest. Kluwer Academic Publisher, Dordrecht, v. 75, n. 1/2, p. 81-86, May 1988.

TABARELLI, M.; MANTOVANI, W. A regeneração de uma floresta tropical montana após corte e queima, São Paulo, Brasil. Revista Brasileira de Biologia, São Paulo, v. 59, n. 2, p. 239250, fev. 1999.

VALCARCEL, R.; ALTERIO, C. F. V. d'. Medidas físicobiológicas de recuperação de áreas degradadas: avaliação das modificações edáficas e fitossociológicas. Floresta e Ambiente, Seropédica, v. 5, n. 1, p. 68-88, jan./dez. 1998.
VANWALLEGHEM, T.; POESEN, J.; EECKHAUT, M. van den; NACHTERGAELE, J.; DECKERS, J. Reconstructing rainfall and land-use conditions leading to the development of old gullies. Holocene, London, v. 15, n. 3, p. 378-386, 2005.

VIEIRA, C. M.; PESSOA, S. V. A. Estrutura e composição florística do estrato herbáceo-subarbustivo de um pasto abandonado na Reserva Biológica de Poço das Antas, município de Silva Jardim, RJ. Rodriguésia, Rio de Janeiro, v. 52, n. 80, p. 17-30, 2001.

WOODS, P. Effects of logging, drought, and fire on structure and composition of tropical forest in Sabah, Malasia. Biotropica, Washington, v. 21, n. 4, p. 290-298, 1989.

WUNDERLE JUNIOR, J. M. The role of animal seed dispersal in accelerating native forest regeneration on degraded tropical lands. Forest Ecology and Management, Amsterdam, v. 99, n. 1/2, p. 233-235, 1997. 